\title{
Um estudo da produção escrita de estudantes do Ensino Médio em questões de Ciências do PISA
}

\author{
A study of the written production of the high school students on Science \\ Questions of PISA
}

\author{
Jeferson Ferreti Ribas ${ }^{1}$ \\ Fabiele Cristiane Dias Broietti ${ }^{2}$
}

\section{Resumo}

Pesquisas têm ressaltado a necessidade de uma educação em Ciências em que os indivíduos sejam capazes de desenvolver ideias e maneiras científicas de pensar, resolver problemas e tomar decisões na vida pessoal, cívica e profissional, enfatizando a importância do Letramento Científico. Em meio a esse contexto, neste artigo apresenta-se uma investigação da produção escrita de estudantes do Ensino Médio em três questões de Ciências do PISA que abordam conceitos químicos das temáticas Ozônio, Brilho Labial e Massa de Pão, respectivamente, a fim de evidenciar algumas tendências de respostas, possíveis dificuldades apresentadas e conhecimentos científicos mobilizados para a resolução das questões. Por meio dos procedimentos da Análise de Conteúdo, constatou-se que a maioria das produções escritas investigadas ressaltou possíveis dificuldades dos estudantes quanto à utilização de linguagem científica para explicar/justificar fenômenos químicos e/ou lidar corretamente com as informações das questões para produzir argumentos e conclusões fundamentados em evidências científicas. Nesse sentido, verificouse que as dificuldades dos estudantes podem estar relacionadas à não compreensão de alguns aspectos do Letramento Científico como determinados conceitos científicos e alguns processos de investigação.

Palavras chave: produção escrita; questões de ciências; PISA; letramento científico.

\section{Abstract}

Researches highlight the demand for a Science education in which individuals are able to develop scientific ideas and ways of thinking, solving problems, and making decisions in their personal, civic, and professional lives, emphasizing the importance of Scientific Literacy. In this context, this article presents an investigation of the written production of high school students on three PISA Science questions that address chemical concepts, concerning the themes of Ozone, Lip Gloss, and Bread Dough. The aim is to highlight possible answers trends, difficulties, and scientific knowledge mobilized to solve the proposed questions. By applying the Content Analysis procedures, it was found that most of the investigated written productions highlight possible difficulties of students regarding the use of scientific language

\footnotetext{
${ }^{1}$ Universidade Estadual de Londrina |jferretiribas@gmail.com

2 Universidade Estadual de Londrina | fabielediasquimica@gmail.com
} 
to explain/justify chemical phenomena. Another difficulty dealing correctly with the questions information to produce arguments and conclusions based on scientific evidence. In this sense, the student difficulties may be related to the misunderstanding of some aspects of Scientific Literacy, such as certain scientific concepts and some investigation processes.

Keywords: written production; sciences questions; PISA; scientific literacy.

\section{Considerações iniciais}

Documentos brasileiros como BNCC ${ }^{3}, \mathrm{PCNEM}^{4}, \mathrm{PCN}^{5}, \mathrm{OCEM}^{6}$ e a literatura especializada da área têm frisado a necessidade de uma educação em Ciências capaz de desenvolver ideias e maneiras científicas de pensar, de modo que habilite o cidadão a viver e a trabalhar em uma sociedade do conhecimento (TENREIRO VIEIRA; VIEIRA, 2013). Segundo estes mesmos autores,

[...] o ensino das Ciências deve ser visto, em primeiro lugar, como promotor da Literacia Científica. Isso porque a crescente importância do conhecimento científico exige uma população cientificamente literada, ou seja, uma população de seguir debates científicos e envolver-se nas questões que a tecnologia coloca, quer para eles como indivíduos, quer para a sociedade como um todo (TENREIRO VIEIRA; VIEIRA, 2013, p. 164).

A Literacia Científica tem sido apontada e reconhecida como a meta primeira da educação em Ciências na escola. Embora haja tal concordância, não há consenso entre os autores da área quanto ao seu significado. A expressão tem sido usada com múltiplas interpretações que refletem diferentes quadros de referência. A diversidade das perspectivas repercute, inclusive, nas designações empregadas: Compreensão Pública da Ciência, Cultura Científica, Literacia Científica, Alfabetização Científica, Letramento Científico, entre outras (TENREIRO-VIEIRA; VIEIRA, 2013).

Embora haja distintas nomenclaturas, concorda-se com Sasseron e Carvalho (2011) quando referenciam o objetivo comum desse ensino de Ciências. As autoras reconhecem a pluralidade semântica encontrada na literatura da área, no entanto, salientam que no cerne das discussões levantadas pelos pesquisadores que usam um termo ou outro, estão as mesmas preocupações com o ensino de Ciências, ou seja, um ensino que "almeja a formação cidadã dos estudantes para domínio e uso dos conhecimentos científicos e seus desdobramentos nas mais diferentes esferas de sua vida" (p. 60).

Considerando as diferentes nomenclaturas (Alfabetização Científica, Letramento Científico, Enculturação Científica etc.), nesta investigação foi adotado o termo Letramento Científico, uma vez que este é o termo empregado em documentos que discutem a

\footnotetext{
${ }^{3}$ BNCC. Disponível em: <http://basenacionalcomum.mec.gov.br/images/historico/BNCC_EnsinoMedio_embaix a_site_110518.pdf>. Acesso em: 06 fev. 2020.

${ }^{4}$ PCNEM. Disponível em: <http://portal.mec.gov.br/seb/arquivos/pdf/ciencian.pdf>. Acesso em: 06 fev. 2020.

${ }^{5}$ PCN+. Disponível em: <http://portal.mec.gov.br/seb/arquivos/pdf/CienciasNatureza.pdf>. Acesso em: 06 fev. 2020.

${ }^{6}$ OCEM. Disponível em: <http://portal.mec.gov.br/seb/arquivos/pdf/book_volume_02_internet.pdf>. Acesso em: 06 fev. 2020
} 
proposta do PISA (Programme for International Student Assessment - Programa de Avaliação Internacional de Estudantes).

O Letramento Científico é determinado pela OECD (Organisation for Economic Cooperation and Development - Organização para a Cooperação e Desenvolvimento Econômico) - no contexto do PISA -, com base em quatro principais dimensões de natureza diferenciada: conteúdos, processos, contextos e atitudes (OECD, 2007). A primeira diz respeito ao conhecimento dos estudantes e à sua capacidade de utilizar tais conhecimentos enquanto executam processos cognitivos característicos da Ciência e da investigação científica em contextos de relevância pessoal, social e global. A segunda está relacionada aos processos científicos centrados na capacidade de adquirir, interpretar e agir, baseada em evidências. A terceira dimensão define uma variedade de situações da vida cotidiana, não limitadas ao contexto escolar, que envolvam Ciência e Tecnologia. Por fim, a dimensão das atitudes desempenha um papel significativo no interesse, na atenção e nas reações dos indivíduos frente à Ciência e à Tecnologia.

De acordo com os referenciais do PISA:

Letramento científico é definido como a capacidade de se envolver com as questões relacionadas com a Ciência e com a ideia da Ciência, como cidadão reflexivo. Uma pessoa letrada cientificamente está disposta a participar de discussão fundamentada sobre ciência e tecnologia, o que exige as competências para explicar fenômenos cientificamente, avaliar e planejar investigações científicas e interpretar dados e evidências cientificamente (BRASIL, 2019, p. 22).

O PISA é um programa internacional que procura avaliar o nível educacional de estudantes dos países participantes por meio de provas que abrangem, principalmente, três áreas do conhecimento: Leitura, Matemática e Ciências (BRASIL, 2001). As questões de Ciências desse exame buscam relações com o contexto de vida dos estudantes, referindo-se à importância do Letramento Científico que, de acordo com a Matriz de Avaliação de Ciências do PISA 2015, "requer não apenas o conhecimento de conceitos e teorias da Ciência, mas também o conhecimento sobre os procedimentos e práticas comuns associadas à investigação científica e como eles possibilitam o avanço da Ciência" (OECD, 2013, p.4).

Espera-se que o cidadão letrado cientificamente tenha a habilidade de utilizar seu conhecimento de Ciências, bem como compreender a Ciência como um caminho de novas oportunidades de aprendizagem, participando "plenamente da vida social, econômica e cívica da sociedade moderna em um mundo globalizado" (BRASIL, 2019, p. 130; RIBAS et al., 2015).

Os resultados do PISA são um dos indicadores que evidenciam o insucesso da educação brasileira nas três áreas avaliadas (Leitura, Matemática e Ciências). Diante disso, salienta-se que estudos mais detalhados do desempenho dos brasileiros nesta prova, como por exemplo a análise das questões e da produção escrita dos estudantes nessas questões, poderiam contribuir na busca de um maior entendimento acerca de tais constatações.

Alguns estudos ressaltam a importância em se investigar a produção escrita. Segundo Ribas et al. (2015), compreender a forma como os estudantes se apropriam de um determinado conhecimento que emerge nas suas produções escritas, pode evidenciar dificuldades de aprendizagem desconhecidas pelo professor, pois na maioria das vezes ele apenas sabe aquilo que o estudante acertou ou errou em uma questão, e dificilmente identifica as causas dos erros e as estratégias adotadas durante a sua resolução (PEREGO, 
2006). Nesse sentido, por meio da produção escrita dos estudantes é possível reconhecer estratégias de resolução utilizadas, possíveis dificuldades apresentadas, verificar os erros cometidos, além de ajudar o professor e o estudante a refletirem sobre pontos a serem revistos nos processos de ensino e de aprendizagem (CELESTE, 2008).

Diante do exposto, neste artigo apresenta-se um estudo que teve o objetivo de analisar a produção escrita ${ }^{7}$ de estudantes do Ensino Médio em três questões de Ciências do PISA que abordam conceitos químicos, buscando evidenciar algumas tendências de respostas, as possíveis dificuldades apresentadas e os conhecimentos científicos mobilizados para a resolução das questões.

\section{Contexto da pesquisa e procedimentos metodológicos}

Com o objetivo de conhecer a estrutura e as características da prova do PISA, foram realizados alguns estudos prévios com as questões de Ciências deste exame - presentes no Caderno de Itens Liberados de Ciências do PISA ${ }^{8}$, em um total de 122 - de modo a classificá-las de acordo com as competências e os Conhecimentos de e sobre ${ }^{10}$ Ciências, componente curricular predominante (SALAMANCA NETO et al., 2014), situações e contextos no qual o tema da questão estava inserido e a conformidade do conteúdo específico de Química em 41 das questões que abordam conceitos específicos dessa ciência (BROIETTI et al., 2014). Em ambos os estudos, as questões foram analisadas com base nos referenciais do PISA 2012 - Matriz de Avaliação de Ciências (BRASIL, 2012).

Os dados que compõem a presente investigação referem-se à produção escrita de estudantes em 3 questões de Ciências do PISA. Participaram da pesquisa 46 estudantes do Ensino Médio, com a faixa etária estabelecida pelos referenciais do Programa (15 anos e 3 meses a 16 anos e 2 meses), sendo 29 estudantes da $1^{a}$ Série e 17 da $2^{a}$ Série de uma instituição pública de ensino, localizada no Município de Londrina, PR. Como instrumento para coleta das produções escritas, foi elaborada uma prova contendo 14 questões que abordam conceitos específicos de Química, distribuídas em 6 temas distintos. Vale ressaltar que a pesquisa seguiu as normas estipuladas pelo Comitê de Ética em Pesquisa e obteve aprovação do Comitê de Ética da Universidade Estadual de Londrina.

Neste estudo é apresentada a análise da produção escrita dos estudantes nas questões pertencentes às temáticas Ozônio, Brilho Labial e Massa de Pão, respectivamente. Para respondê-las, os estudantes deveriam mobilizar conhecimentos científicos para:

- Interpretar e explicar o processo químico de formação do ozônio que envolve a combinação de átomos e moléculas para a formação de novas moléculas (Questão de tema Ozônio);

\footnotetext{
${ }^{7}$ A produção escrita, nesta investigação, corresponde às respostas dissertativas e explicações dos estudantes nas questões de Ciências do PISA.

${ }^{8}$ Caderno de Itens Liberados de Ciências do PISA. Disponível em:

<http://download.inep.gov.br/download/interna

cional/pisa/ltens_liberados_Ciencias.pdf>. Acesso em: 05 fev. 2020.

${ }^{9}$ Conhecimento de Ciências refere-se ao conhecimento do mundo natural através dos campos da Física,

Química e Ciências (BRASIL, 2012).

${ }^{10}$ Conhecimento sobre Ciências refere-se ao conhecimento da investigação em Ciências e metas das Ciências (BRASIL, 2012).
} 
- Produzir argumentos e conclusões baseados em evidências científicas ao acessar informações das proporções dos ingredientes de dois cosméticos (Questão de tema Brilho Labial);

- Interpretar e explicar o fenômeno químico de fermentação da massa de pão apresentado em experiências em sistemas aberto e fechado, respectivamente (Questão de tema Massa de Pão).

A produção escrita dos estudantes foi analisada e interpretada seguindo os pressupostos da Análise de Conteúdo (AC) (BARDIN, 2016), uma metodologia empregada para compreender, analisar, sintetizar, descrever e interpretar mensagens emitidas por diferentes meios de comunicação ${ }^{11}$. Essa metodologia tem como fator comum uma hermenêutica baseada na inferência, designando-se como:

Um conjunto de técnicas de análise das comunicações visando obter por procedimentos sistemáticos e objetivos de descrição do conteúdo das mensagens indicadores (quantitativos ou não) que permitam a inferência de conhecimentos relativos às condições de produção/recepção (variáveis inferidas) dessas mensagens (BARDIN, 2016, p. 48).

Nesse sentido, por meio da inferência busca-se evidenciar aquilo que o conteúdo analisado pode ensinar em relação a "outras coisas" (BARDIN, 2016, p. 44).

A Análise de Conteúdo se organiza em torno de três fases: pré-análise, exploração do material, e tratamento dos resultados, inferência e interpretação. A primeira fase está relacionada à escolha, exploração e codificação dos materiais a serem analisados com base nas hipóteses e objetivos da investigação (BARDIN, 2016). Os materiais analisados, nesta pesquisa, correspondem às produções escritas dos estudantes em 3 questões de Ciências do PISA que foram codificadas seguindo uma ordem numérica que variou de 1 a 46 . E $E_{35}$, por exemplo, corresponde à produção escrita do estudante de número 35.

A análise das comunicações contempla a segunda fase da AC, em que os dados brutos são transformados e agregados em unidades fundamentadas a partir de teorias definidas antes de examinar o corpus da pesquisa (a priori) ou pelo surgimento de elementos novos ao longo da análise (teorias emergentes ou a posteriori), sendo variável de acordo com os dados obtidos e os objetivos da investigação. Em seguida, são reunidos elementos semelhantes (recortes do texto: unidades de registro) com a finalidade de produzir as descrições e interpretações possibilitadas pela análise que permite atingir uma representação do conteúdo (BARDIN, 2016). No contexto desta pesquisa, a partir da análise das respostas e explicações dos estudantes (produção escrita) que constam nas unidades de registro, foram estabelecidas categorias emergentes elaboradas por meio da leitura recorrente do corpus, em um processo de leitura e retomada de leitura dos dados.

A última fase da AC refere-se à análise e interpretação dos resultados brutos, tratados ou não por meio de categorias (BARDIN, 2016). Tais resultados, nesta investigação, são provenientes da produção escrita de estudantes do Ensino Médio nas 3 questões de Ciências do PISA que abordam conceitos químicos, apresentados na próxima seção. ${ }^{11}$ Qualquer veículo de significados de um emissor para um receptor, controlado ou não por este (BARDIN, 2016,
p. 38). 


\section{Produção escrita de estudantes em questões de ciências do PISA}

Para compor os resultados, a produção escrita foi analisada de acordo com as respostas esperadas expressas no Caderno de Itens Liberados de Ciências do PISA. A seguir, são apresentados os resultados referentes à questão de tema Ozônio, seguidos da questão de tema Brilho Labial e, por fim, a questão de tema Massa de Pão.

\section{Questão de tema Ozônio}

Na prova do PISA, a questão pertencente ao tema Ozônio apresenta como suporte a seção de um artigo a respeito da camada de ozônio e um diagrama que mostra a concentração do gás ozônio na atmosfera. A questão utilizada como instrumento de investigação é apresentada no Quadro 1, a seguir:

\section{Quadro 1 - Questão de tema Ozônio}

No texto nada é mencionado com relação ao modo como o ozônio é formado na atmosfera. Na verdade, todos os dias certa quantidade de ozônio é formada e certa quantidade de ozônio desaparece. O modo como o ozônio é formado está ilustrado nos quadrinhos abaixo:
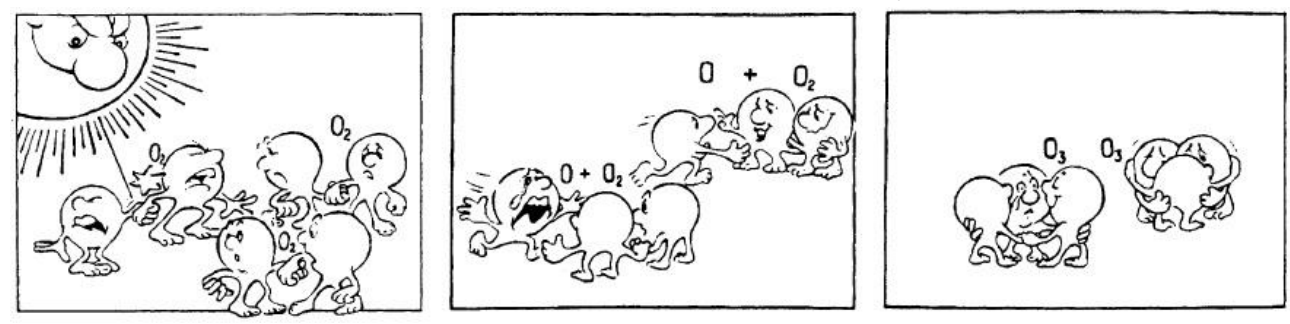

Suponha que você tenha um tio que tente entender o significado desta tira. Ele, entretanto, nunca estudou Ciências na escola e não entende o que o autor do desenho está explicando. Ele sabe que não há companheiros pequeninos na atmosfera, mas pergunta o que esses companheirinhos do desenho representam, o que essas estranhas notações $\mathrm{O}_{1}, \mathrm{O}_{2}$ e $\mathrm{O}_{3}$ representam e quais processos o desenho representa. Seu tio pede para que você lhe explique os quadrinhos. Escreva uma explicação dos quadrinhos para seu tio.

Fonte: Adaptado do Caderno de Itens Liberados de Ciências do PISA (Questão 1, p. 32)

De acordo com os estudos de Broietti et al. (2014) e com base nos referenciais do PISA, a questão de tema Ozônio exige a competência Explicar fenômenos cientificamente. Ao resolvê-la, o estudante deve mobilizar o conhecimento científico, levando em conta a combinação de átomos e moléculas para a formação de novas moléculas. Em situações específicas, o estudante deve identificar quais moléculas têm suas ligações químicas rompidas para a formação de outras, e explicar o fenômeno ocorrido.

Segundo o Caderno de Itens Liberados de Ciências do PISA, para responder corretamente à questão, os estudantes deveriam levar em conta 3 aspectos de respostas apresentados no Quadro 2, a seguir: 
Quadro 2 - Respostas esperadas para a questão de tema Ozônio

- Algumas moléculas de oxigênio (cada uma composta por dois átomos de oxigênio) são quebradas em átomos de oxigênio (o que corresponde à explicação da figura 1 da questão);

- A quebra (das moléculas de oxigênio) acontece sob a influência da luz do sol (o que corresponde também à explicação da figura 1 da questão);

- Os átomos de oxigênio se combinam com outras moléculas de oxigênio para formar moléculas de ozônio (o que corresponde à explicação das figuras 2 e 3, respectivamente, da questão).

Fonte: Adaptado do Caderno de Itens Liberados de Ciências do PISA (Ozônio - Correção 1, p. 32-33)

Como na prova do PISA, neste estudo foi adotada a mesma atribuição de notas para as respostas dos estudantes investigados. Assim, receberam Nota 3 na questão de tema Ozônio, os estudantes que mencionaram todos os aspectos de respostas esperados, Nota 2, aqueles que mencionaram pelo menos dois aspectos e, Nota 1, os estudantes que mencionaram apenas um dos três aspectos. Aos estudantes que não responderam à questão $\left(\mathrm{E}_{01} ; \mathrm{E}_{6} ; \mathrm{E}_{28}\right)$ ou que não mencionaram ao menos um dos aspectos de respostas esperados, foi atribuída Nota 0 (zero) à sua produção escrita.

De acordo com a correção e atribuição de notas, verificou-se que apenas dois estudantes (4,34\% dos investigados) contemplaram pelo menos um dos três aspectos de respostas esperados, enquanto 44 (95,66\% dos investigados) receberam, em suas produções escritas, Nota 0, uma vez que não contemplaram nenhum dos aspectos de respostas esperados para a questão.

Receberam Notas 3 e 2 as respostas dos estudantes $E_{25}$ e $E_{46}$, respectivamente. Seguem as respostas dos estudantes:

Tinham 3 moléculas de oxigênio com 2 átomos cada e 1 dessas moléculas se separou por causa do sol e foi para a outra molécula formando 2 trios com 3 átomos chamado de ozônio. $\left(E_{25}\right)$

Cada personagem é um átomo de oxigênio, cada dupla é uma molécula de oxigênio. Quando uma dupla de átomos se desfaz e formam dois trios, que é o $\mathrm{O}_{3}$, formam duas moléculas de ozônio. $\left(\mathrm{E}_{46}\right)$

Por meio da produção escrita de $E_{25}$, percebe-se que o estudante reconhece o átomo de oxigênio e que a união de dois destes átomos forma uma molécula de oxigênio. Verificase, ainda, que $E_{25}$ entende que uma das moléculas de oxigênio "se quebra" devido à influência da luz solar, fazendo referência ao que mostra a primeira figura da questão, demonstrando compreender que a molécula de oxigênio se separa em dois átomos de oxigênio, e que esses átomos se ligam a outras moléculas de oxigênio formando, assim, moléculas de ozônio, fazendo referência ao que mostram as figuras 2 e 3 da questão, respectivamente. Sua resposta contempla os três aspectos exigidos pelos referenciais de correção do PISA.

$\mathrm{O}$ estudante $\mathrm{E}_{46}$ não menciona $\mathrm{O}$ aspecto que se refere à "quebra" da molécula de oxigênio devido à luz solar, por isso recebeu Nota 2 em sua resposta. O estudante demonstra conhecer as representações de átomo e molécula de oxigênio, respectivamente, e da molécula de ozônio. E, apesar de não descrever detalhadamente, entende-se que ele compreende o processo de quebra de ligações entre as moléculas de oxigênio e a formação de novas ligações entre átomos e moléculas de oxigênio, originando as moléculas de ozônio. 
Quadro 3 - Categorias que emergiram a partir das respostas à questão de tema Ozônio

\begin{tabular}{|c|c|c|}
\hline $\begin{array}{l}\text { Categorias / } \\
\text { Estudantes }\end{array}$ & Descrição & Exemplos de Produções Escritas \\
\hline $\begin{array}{l}\text { 1. Visão animista } \\
\left(E_{08} ; E_{09} ; E_{11} ; E_{14} ; E_{20} ;\right. \\
E_{21} ; E_{22} ; E_{27} ; E_{29} ; E_{30} ; \\
\left.E_{34} ; E_{40} ; E_{45}\right)\end{array}$ & $\begin{array}{l}\text { Respostas que atribuem } \\
\text { sentimentos, carregadas de } \\
\text { metáforas, tendo por base o } \\
\text { ser vivente, ou seja, atribui } \\
\text { características humanas a } \\
\text { átomos, moléculas, } \\
\text { substâncias químicas. }\end{array}$ & $\begin{array}{l}\text { No } 1^{\circ} \text { quadrinho o sol está prejudicando os } \\
\text { "companheiros", que ficam nervosos e se juntam } \\
\left.\text { para juntos se protegerem. ( } E_{14}\right) \\
\mathrm{O}_{2} \text { e } \mathrm{O}_{1} \text { estão muito tristes, pois estão a muito } \\
\text { tempo protegendo a Terra, então eles } \\
\text { encontraram um casal de } \mathrm{O}_{2} \text { e se juntam com eles } \\
\text { para descansar, fazer amizade e se divertir, então } \\
\text { eles se transformam em } \mathrm{O}_{3} .\left(\mathrm{E}_{30}\right)\end{array}$ \\
\hline $\begin{array}{l}\text { 2. Notações } \\
\text { químicas } \\
\left(E_{02} ; E_{07} ; E_{10} ; E_{11} ; E_{19} ;\right. \\
\left.E_{22} ; E_{33} ; E_{38}\right)\end{array}$ & $\begin{array}{l}\text { Respostas que definem } \mathrm{O}_{1} \\
\text { como a representação do } \\
\text { átomo de oxigênio ou } \\
\text { elemento químico; } \mathrm{O}_{2} \text { como } \\
\text { molécula de oxigênio e } \mathrm{O}_{3} \\
\text { como molécula de ozônio. }\end{array}$ & $\begin{array}{l}\text { Esses pequeninos que estão com o } 3 \text { são uma } \\
\text { molécula de ozônio... e os que estão com } 2 \text { são } \\
\text { moléculas de oxigênio que são compostas por } 2 \\
\left.\text { átomos de oxigênio. ( } E_{02}\right) \\
\mathrm{O}_{1} \mathrm{O}_{2} \mathrm{O}_{3} \text { a letra } \mathrm{O} \text { é um elemento químico e os } \\
\text { números são a quantidade de átomos... o ozônio } \\
\left.\text { ele precisa de três átomos de oxigênio. ( } \mathrm{E}_{19}\right)\end{array}$ \\
\hline $\begin{array}{l}\text { 3. Camada de } \\
\text { Ozônio } \\
\left(E_{03} ; E_{04} ; E_{07} ; E_{10} ; E_{15} ;\right. \\
\left.E_{20} ; E_{38} ; E_{39}\right)\end{array}$ & $\begin{array}{l}\text { Respostas que se referem à } \\
\text { formação da molécula de } \\
\text { ozônio ou Camada de } \\
\text { Ozônio e/ou sua função. }\end{array}$ & $\begin{array}{l}\text { No quadrinho representa a formação da camada } \\
\text { de ozônio da terra. }\left(E_{04}\right) \\
\text { Representam a formação do ozônio... a união } \\
\text { delas funciona como um escudo protetor dos raios } \\
\text { prejudiciais a vida... }\left(E_{15}\right)\end{array}$ \\
\hline $\begin{array}{l}\text { 4. Termos químicos } \\
\text { definidos } \\
\text { incorretamente } \\
\left(E_{07} ; E_{22} ; E_{24} ; E_{26} ; E_{34 ;}\right. \\
\left.E_{41} ; E_{43}\right)\end{array}$ & $\begin{array}{l}\text { Definição incorreta de } \\
\text { elemento químico, átomo e } \\
\text { molécula. }\end{array}$ & $\begin{array}{l}{[\ldots] \text { esses companheirinhos são as moléculas... }} \\
\left(E_{34}\right) \\
\text { Eles (quadrinhos) representam a formação dos } \\
\left.\text { átomos... (E } E_{35}\right)\end{array}$ \\
\hline $\begin{array}{l}\text { 5. Influência da luz } \\
\text { solar } \\
\left(E_{38} ; E_{41} ; E_{44} ; E_{45}\right)\end{array}$ & $\begin{array}{l}\text { Respostas que indicam a } \\
\text { influência da luz solar na } \\
\text { formação da molécula de } \\
\text { ozônio ou da Camada de } \\
\text { Ozônio. }\end{array}$ & $\begin{array}{l}\text { Cada um desses pequeninos são átomos de } \\
\text { oxigênio, que quando atingidos pelos raios solares, } \\
\text { se unem em três partículas de oxigênio, formando } \\
\left.\text { então a molécula de ozônio. ( } E_{38}\right)\end{array}$ \\
\hline $\begin{array}{l}\text { 6. Ar atmosférico / } \\
\text { gases } \\
\left(E_{05} ; E_{42} ; E_{43}\right)\end{array}$ & $\begin{array}{l}\text { Refere-se às moléculas de } \\
\text { oxigênio e/ou ozônio como } \\
\text { ar atmosférico ou gases. }\end{array}$ & $\begin{array}{l}\text { No primeiro quadro são moléculas de ar... }\left(E_{42}\right) \\
\text { Essas notações }\left(\mathrm{O}_{1}, \mathrm{O}_{2} \text { e } \mathrm{O}_{3}\right) \text { são gases... }\left(\mathrm{E}_{43}\right)\end{array}$ \\
\hline $\begin{array}{l}\text { 7. Respostas sem } \\
\text { sentido ou confusas } \\
\left(E_{02} ; E_{12} ; E_{13} ; E_{16} ; E_{17} ;\right. \\
E_{18} ; E_{23} ; E_{26} ; E_{31} ; E_{32} ; \\
\left.E_{33} ; E_{35} ; E_{36} ; E_{37}\right)\end{array}$ & $\begin{array}{l}\text { Respostas que apresentam } \\
\text { confusão na explicação. }\end{array}$ & $\begin{array}{l}\text { Esses pequeninos que estão com o } 3 \text { são uma } \\
\text { molécula de ozônio que possui } 3 \text { átomos de } \\
\text { ozônio e os que estão com } 2 \text { são moléculas de } \\
\text { oxigênio que são compostas por } 2 \text { átomos de } \\
\text { oxigênio. (E } E_{02} \text { ) } \\
\text { A camada de ozônio é formada por pequenas } \\
\text { moléculas diferentes, os } \mathrm{O}_{1}, \mathrm{O}_{2} \text { e } \mathrm{O}_{3} \text {, esses } \\
\text { componentes separados não tem função, mas } \\
\text { quando há o encontro químico certo ele vira um } \\
\text { ozônio bom e protege o mundo. ( } \mathrm{E}_{26} \text { ) }\end{array}$ \\
\hline
\end{tabular}

Aproximadamente $96 \%$ dos estudantes investigados obtiveram Nota 0 em suas respostas para a questão de tema Ozônio. Isso não quer dizer que eles tenham errado completamente, apenas não apresentaram em suas respostas nenhum dos aspectos 
exigidos pelos referenciais de correção do PISA. Diante disso, para melhor composição dos resultados, suas produções escritas foram analisadas e agrupadas em categorias, como apresentado no Quadro 3.

Ao investigar a produção escrita dos estudantes que obtiveram Nota 0 na questão de tema Ozônio, constatou-se o predomínio de respostas que se enquadram nas categorias 7 - Respostas sem sentido ou confusas - e 1 - Visão animista -, respectivamente.

Ainda que autores destaquem que o uso de analogias, ilustrações, metáforas e modelos como recurso didático na explicação de termos e/ou fenômenos científicos podem auxiliar na melhor compreensão de um domínio desconhecido pelos estudantes (NARDI; ALMEIDA, 2006), é preciso ter cuidado para que o uso desses recursos não crie obstáculos epistemológicos de aprendizagem. Para Barros (2010), o obstáculo animista é aquele em que "os fenômenos são explicados através de analogias com comportamentos humanos", ou seja, a visão animista dá características de seres vivos a objetos inanimados, como verificado nas respostas dos estudantes (Categoria 1) ao atribuírem sentimentos a átomos e moléculas.

A alta porcentagem $(95,65 \%)$ de estudantes que obtiveram Nota 0, de acordo com os aspectos exigidos no referencial do PISA, não indica que eles não detenham conhecimentos acerca dos conceitos abordados, uma vez que alguns deles conseguiram identificar notações químicas definindo corretamente os conceitos de átomos e moléculas (Categoria 2), porém apresentaram dificuldades em utilizar uma linguagem científica para explicar o fenômeno científico apresentado na figura da questão analisada, principalmente no que diz respeito à quebra de ligações entre átomos de uma molécula $\left(\mathrm{O}_{2}\right)$ e a formação de novas moléculas $\left(\mathrm{O}_{3}\right)$.

De acordo com o NRC (2012), a educação em Ciências deve possibilitar aos estudantes "construir explicações logicamente coerentes de fenômenos que incorporem seu entendimento atual da Ciência, ou um modelo que os represente [...]" (p. 52, tradução nossa). Entretanto, se o estudante não compreende o conceito científico, é evidente que apresentará dificuldades para mobilizar uma linha de raciocínio e explicações para o fenômeno em questão.

Na sequência, são apresentados os resultados provenientes da análise da produção escrita dos estudantes na questão de tema Brilho Labial.

\section{Questão de tema Brilho Labial}

A segunda questão utilizada como instrumento de investigação da produção escrita de estudantes do Ensino Médio é apresentada no Quadro 4.

A questão de tema Brilho Labial exige a competência Usar evidência científica. Para resolvê-la, o estudante deve acessar informações e produzir argumentos e conclusões baseados em evidências científicas. Ao analisar as informações a respeito do brilho labial ser mais macio e cremoso que o batom, além de examinar os ingredientes e o modo de preparo de ambos os cosméticos, o estudante deve evidenciar os ingredientes responsáveis pela característica desejada do batom (BROIETTI et al., 2014). 
Quadro 4 - Questão de tema Brilho Labial

Abaixo há duas receitas diferentes de cosméticos que você mesmo pode fazer. O batom é mais firme do que o brilho labial, que é macio e cremoso.

Ingredientes:

\section{Brilho labial}

$5 \mathrm{~g}$ de óleo de rícino - 0,2 g de cera de abelha - 0,2 g de cera de carnaúba - 1 colher de chá de corante - 1 gota de essência alimentar.

Modo de fazer: Aqueça o óleo e as ceras em banho-maria até que a mistura fique homogênea. Em seguida, adicione o corante e a essência. Misture tudo.

Ingredientes:

\section{Batom}

$5 \mathrm{~g}$ de óleo de rícino - $1 \mathrm{~g}$ de cera de abelha - $1 \mathrm{~g}$ de cera de carnaúba - 1 colher de chá de corante - 1 gota de essência alimentar.

Modo de fazer: Aqueça o óleo e as ceras em banho-maria até que a mistura fique homogênea. Em seguida, adicione o corante e a essência. Misture tudo.

Para a fabricação do brilho labial e do batom, o óleo e as ceras são misturados. O corante e a essência são adicionados, em seguida. O batom fabricado com essa receita é firme, portanto difícil de usar. Para obter um batom mais macio, que mudanças você faria na proporção dos ingredientes?

Fonte: Adaptado do Caderno de Itens Liberados de Ciências do PISA (Questão 1, p. 80)

Assim como na questão de tema Ozônio, a produção escrita dos estudantes para esta questão também foi analisada de acordo com as respostas esperadas expressas no Caderno de Itens Liberados de Ciências do PISA. O Quadro 5, a seguir, apresenta as respostas esperadas para a questão:

Quadro 5 - Respostas esperadas para a questão de tema Brilho Labial

\section{Crédito Completo}

Código 1: Respostas indicando que é preciso adicionar menos cera E/OU mais óleo.

- Poderíamos usar um pouco menos de cera de abelha e carnaúba.

- Adicionar mais óleo de rícino.

\section{Nenhum Crédito}

Código 0: Outras respostas.

- Aquecer a mistura por mais tempo, pois isso o deixará mais macio.

Código 9: Não respondeu.

Fonte: Adaptado do Caderno de Itens Liberados de Ciências do PISA (Brilho Labial - Correção 1, p.

Responderam corretamente à questão de tema Brilho Labial cerca de 17 estudantes (36,96\%) e receberam Código 1 em suas produções escritas. Dois estudantes, além de mencionarem a diminuição da quantidade de cera, propuseram aumentar a quantidade de óleo de rícino à formulação da receita do batom para se obter um cosmético mais macio. 0 Código 0 foi atribuído a 28 estudantes (60,87\%), pois mencionaram outras mudanças que não estão de acordo com o que está previsto no Caderno de Itens Liberados de Ciências do PISA; e apenas 1 estudante $\left(\mathrm{E}_{06}\right)$ recebeu Código 9.

Para responder à questão de tema Brilho Labial corretamente, os estudantes deveriam comparar as proporções dos ingredientes presentes na receita do batom e na receita do 
brilho labial, e identificar que para preparar o brilho labial, a quantidade usada de ceras (abelha e carnaúba) é menor em relação à receita do batom, resultando num produto mais macio e cremoso. $O$ enunciado e o suporte da questão não explicitam que a quantidade de óleo influencia na obtenção de um produto mais macio, uma vez que as duas receitas apresentam a mesma quantidade desse ingrediente $(5 \mathrm{~g})$; mas por se tratar de um ingrediente líquido, os estudantes deveriam supor que aumentando sua quantidade na receita do batom, isso favoreceria a obtenção de um cosmético com o aspecto desejado.

Quadro 6 - Categorias que emergiram a partir das respostas à questão sobre o tema Brilho Labial

\begin{tabular}{|c|c|c|}
\hline $\begin{array}{l}\text { Categorias / } \\
\text { Estudantes }\end{array}$ & Descrição & Exemplos de Produções Escritas \\
\hline $\begin{array}{l}\text { 1. Aumento da } \\
\text { quantidade de cera } \\
\left(E_{07} ; E_{10} ; E_{12} ; E_{13} ; E_{19 ;}\right. \\
\left.E_{20} ; E_{28} ; E_{36} ; E_{37}\right)\end{array}$ & $\begin{array}{l}\text { Respostas mencionando que } \\
\text { o aumento da quantidade } \\
\text { das ceras à formulação do } \\
\text { batom leva a um cosmético } \\
\text { mais macio. }\end{array}$ & $\begin{array}{l}\text { Adicionaria mais cera de abelha e de carnaúba. }\left(E_{07}\right) \\
\text { Colocaria mais cera. }\left(E_{12}\right) \\
\text { Aumentaria em mais um grama a cera de abelha e a } \\
\text { cera de carnaúba. }\left(E_{36}\right)\end{array}$ \\
\hline $\begin{array}{l}\text { 2. Substituição e/ou } \\
\text { a retirada de algum } \\
\text { ingrediente } \\
\left(E_{23} ; E_{29} ; E_{35} ; E_{39} ; E_{42 i}\right)\end{array}$ & $\begin{array}{l}\text { Respostas indicando a } \\
\text { substituição e/ou a retirada } \\
\text { de algum ingrediente da } \\
\text { formulação do batom para } \\
\text { obter um cosmético mais } \\
\text { macio. }\end{array}$ & $\begin{array}{l}\text { Trocaria as ceras por um ingrediente mais macio. } \\
\left(\mathrm{E}_{23}\right) \\
\text { Retiraria o óleo e as ceras, por isso ele não fica } \\
\text { macio, e colocaria outra coisa no lugar que poderia } \\
\text { deixar ele macio. }\left(\mathrm{E}_{39}\right)\end{array}$ \\
\hline $\begin{array}{l}\text { 3. Adiç̧ão de água } \\
\left(E_{01} ; E_{10} ; E_{24} ; E_{29}\right)\end{array}$ & $\begin{array}{l}\text { Respostas que mencionam } \\
\text { que para se obter um batom } \\
\text { mais macio, deve-se } \\
\text { adicionar água à sua } \\
\text { formulação. }\end{array}$ & $\begin{array}{l}\text { Adicionaria água. }\left(E_{24}\right) \\
\text { Tiraria um pouco de cera e colocaria um pouco de } \\
\text { água. }\left(E_{29}\right)\end{array}$ \\
\hline $\begin{array}{l}\text { 4. Influência da } \\
\text { temperatura } \\
\left(E_{02} ; E_{08} ; E_{10}\right)\end{array}$ & $\begin{array}{l}\text { Respostas que indicam a } \\
\text { influência da temperatura na } \\
\text { fabricação do batom. }\end{array}$ & $\begin{array}{l}\left.\text { Não aqueceria o óleo, nem a cera. ( } E_{08}\right) \\
\text { Essa mudança ocorreria adicionando ou } \\
\text { aumentando a quantidade de cera e aquecendo-a } \\
\text { em uma temperatura maior. Adicionar também uma } \\
\text { quantidade de água. }\left(E_{10}\right)\end{array}$ \\
\hline $\begin{array}{l}\text { 5. Diminuição da } \\
\text { quantidade de óleo } \\
\qquad\left(E_{26} ; E_{37}\right)\end{array}$ & $\begin{array}{l}\text { Respostas que mencionam } \\
\quad \text { que a diminuição da } \\
\text { quantidade de óleo de rícino } \\
\text { à formulação do batom, leva } \\
\text { a um cosmético mais macio. }\end{array}$ & $\begin{array}{l}\text { Para o batom ficar macio, diminuiria uns } 40 \% \text { da } \\
\text { quantidade de óleo e cera. Ele ficaria melhor, mas } \\
\text { não mole. }\left(E_{26}\right) \\
\text { Diminuiria o óleo de rícino e aumentaria a cera de } \\
\text { abelha. }\left(E_{37}\right)\end{array}$ \\
\hline $\begin{array}{l}\text { 6. Quantidade de } \\
\text { ceras igual ou } \\
\text { inferior ao brilho } \\
\text { labial } \\
\quad\left(E_{21} ; E_{41}\right)\end{array}$ & $\begin{array}{l}\text { Respostas indicando que } \\
\text { para se obter um batom } \\
\text { mais macio, a quantidade de } \\
\text { ceras deve ser igual ou } \\
\text { inferior à quantidade desses } \\
\text { ingredientes da formulação } \\
\text { do brilho labial. }\end{array}$ & $\begin{array}{l}\text { Eu mudaria a quantidade da cera de abelha e da } \\
\text { cera de carnaúba. Para a cera de abelha adicionaria: } \\
0,1 \mathrm{~g} \text {. Para a cera de carnaúba adicionaria: 0,2 g. } \\
\left(\mathrm{E}_{21}\right) \\
\text { Retiraria } 0,8 \mathrm{~g} \text { de cada tipo de cera que são usadas } \\
\text { no batom, deixando-as com a quantidade de 0,2 g, } \\
\text { assim como o brilho. E finalmente o batom ficará tão } \\
\text { macio quanto o brilho labial. }\left(\mathrm{E}_{41}\right)\end{array}$ \\
\hline $\begin{array}{c}\text { 7. Nenhuma } \\
\text { alteração / } \\
\text { Respostas confusas } \\
\left(E_{27} ; E_{40} / E_{18 ;} E_{34 ;} E_{38 i}\right. \\
\left.E_{44 ;} E_{45}\right)\end{array}$ & $\begin{array}{l}\text { Respostas que indicam que } \\
\text { não deveria ser feita } \\
\text { nenhuma alteração à } \\
\text { formulação do batom; } \\
\text { Confusas. }\end{array}$ & $\begin{array}{l}\text { Nenhuma. Porque do jeito que está, está ótimo. }\left(E_{27}\right) \\
\text { Não misturaria o óleo de rícino e as ceras de abelha. } \\
\left(E_{18}\right) \\
\text { Diminuiria a quantidade dos ingredientes ou } \\
\text { aumentaria a quantidade do óleo. }\left(E_{38}\right)\end{array}$ \\
\hline
\end{tabular}


A seguir, são apresentados alguns exemplos das produções escritas que receberam Código 1:
Adicionaria mais óleo e menos cera. $\left(E_{15}\right)$
Colocaria um pouco menos de cera ou aumentaria a quantidade de óleo para dar uma macies no batom. $\left(E_{30}\right)$
Diminuiria a quantidade de cera de abelha e de carnaúba, pois são esses ingredientes que mudam a consistência do batom, tanto que no brilho labial é pouco a quantidade usada. $\left(E_{43}\right)$
Colocaria uma quantidade menor das ceras, menor de um grama e maior que 0,2 grama. $\left(E_{14}\right)$

Os estudantes $E_{15}$ e $E_{30}$ mencionam, em suas respostas, as duas possibilidades de mudança na proporção dos ingredientes, ou seja, diminuir a quantidade de ceras e/ou aumentar a quantidade de óleo. Já o estudante $\mathrm{E}_{43}$ responde que diminuiria a quantidade de ceras, identificando sua influência na característica do batom, fato este que o distingue do brilho labial; já o estudante $\mathrm{E}_{14}$ responde que diminuiria a quantidade de ceras, evidenciando que essa mudança não poderia ser tanta, a ponto de chegar à mesma quantidade do brilho labial $(0,2 \mathrm{~g})$.

As respostas dos 28 estudantes que receberam Código 0 foram analisadas e agrupadas em categorias, como apresentado no Quadro 6.

Apesar de documentos como o NRC (2012) indicarem que durante a Educação Básica espera-se que os estudantes recebam uma educação em Ciências promotora do Letramento Científico de modo que Ihes possibilite construir e discutir argumentos a partir de conhecimentos, raciocínios e evidências científicas, mostrando como os dados apoiam a argumentação; considerando as respostas apresentadas pelos estudantes para a questão de tema Brilho Labial, verificou-se que 60,87\% deles não conseguiram produzir argumentos e conclusões baseadas em evidências científicas.

Ao invés de utilizarem as informações contidas no enunciado e no suporte da questão para compor suas respostas, esses estudantes apresentaram outros aspectos tais como aumento da quantidade de cera, substituição ou retirada de algum ingrediente, adição de água, influência da temperatura e diminuição da quantidade de óleo.

Alguns estudantes demonstraram compreender que as ceras são responsáveis pelo aspecto macio e cremoso dos cosméticos e sugeriram modificações na proporção desses ingredientes, porém, de forma a não se obter um batom com a característica desejada $\left(E_{21}\right.$ e $E_{41}$ ). Alguns estudantes ainda se limitaram apenas ao procedimento experimental em suas respostas ou sugeriram a adição de água à formulação do batom. Contudo, o procedimento experimental (modo de preparo) e a adição de água não influenciam na consistência dos cosméticos, uma vez que as etapas de preparo são idênticas e a água não compõe os ingredientes de ambos.

$\mathrm{Na}$ continuidade, apresenta-se a análise das produções escritas dos estudantes na questão de tema Massa de Pão.

\section{Questão de tema Massa de Pão}

A terceira questão utilizada como instrumento de investigação da produção escrita de estudantes do Ensino Médio é apresentada no Quadro 7: 
Quadro 7 - Questão de tema Massa de Pão

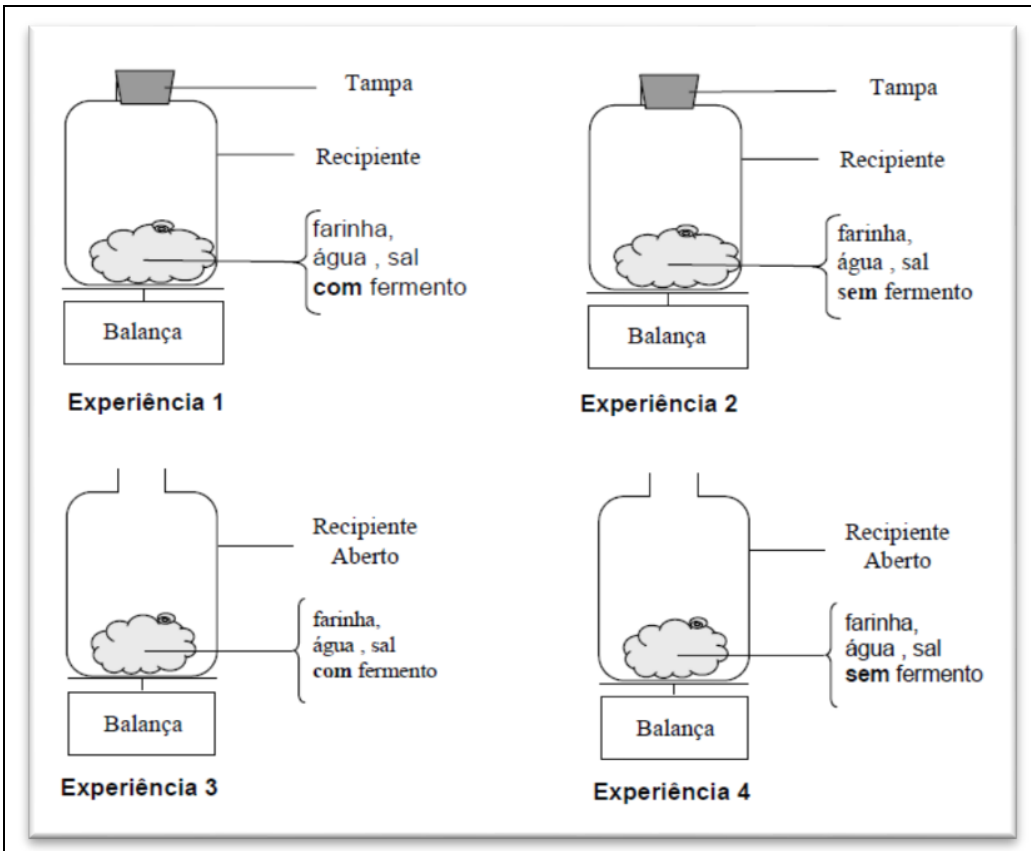

Para fazer massa de pão, um cozinheiro mistura farinha, água, sal e fermento biológico. Após misturar a massa, ela é colocada em um recipiente por várias horas, a fim de permitir que o processo de fermentação ocorra. A fermentação é uma reação química na mistura: o fermento (um fungo unicelular) transforma o amido e os açúcares da farinha em dióxido de carbono e álcool.

Algumas horas depois de misturar os ingredientes, o cozinheiro pesa a mistura e observa que a mistura está pesando menos. A massa (medida física) da mistura para se fazer o pão é a mesma no início de cada uma das quatro experiências mostradas ao lado. Quais são as duas experiências que o cozinheiro deveria comparar para averiguar se é o fermento que causa a perda de massa na mistura?

A) O cozinheiro deveria comparar as experiências 1 e 2 .

B) $O$ cozinheiro deveria comparar as experiências 1 e 3 .

C) $O$ cozinheiro deveria comparar as experiências 2 e 4 .

D) $O$ cozinheiro deveria comparar as experiências 3 e 4 .

Explique sua resposta:

Fonte: Adaptado do Caderno de Itens Liberados de Ciências do PISA (Questão 2, p. 87)

De acordo com o relatório da OECD (2007), ao selecionar uma resposta adequada para a questão Massa de Pão, o estudante deve identificar a variável a ser modificada (presença/ausência de fermento) e as variáveis a serem controladas (outros ingredientes). Além disso, o estudante deve reconhecer que a presença da tampa do recipiente que contém a massa de pão pode evitar que o gás escape, em comparação com a situação simulada. A questão exige a competência Identificação de questões científicas (BROIETTI et al., 2014).

Quadro 8 - Resposta esperada para a questão de tema Massa de Pão

Crédito completo

Código 1: D. O cozinheiro deveria comparar as experiências 3 e 4.

Nenhum crédito

Código 0: Outras respostas.

Código 9: Não respondeu.

Fonte: Adaptado do Caderno de Itens Liberados de Ciências do PISA (Massa de Pão - Correção 2, p. 87)

A produção escrita dos estudantes na questão de tema Massa de Pão foi analisada de acordo com as respostas esperadas expressas no Caderno de Itens Liberados de Ciências do PISA, conforme apresentado no Quadro 8. 
Mediante essa correção, receberam Código 1 as respostas de 12 estudantes que assinalaram a alternativa " $\mathrm{D}$ " da questão de tema Massa de Pão (26,09\% dos investigados). Já as respostas de 33 estudantes receberam Código 0, correspondendo a 72,74\% dos sujeitos, e apenas um estudante (2,17\% dos investigados) não respondeu à questão, recebendo Código 9 em sua resposta.

Para análise da produção escrita dos estudantes na questão Massa de Pão, foi solicitado que eles explicassem sua resposta.

Os estudantes deveriam comparar as experiências para verificar se o fermento é o causador da perda de massa na mistura (massa de pão), levando em conta que um frasco tem fermento e o outro não. Os estudantes também deveriam levar em consideração os tipos de sistema - frasco com tampa (sistema fechado) ou sem tampa (sistema aberto).

Se o fermento estiver em boas condições, nos sistemas contendo esse ingrediente ocorre a reação de fermentação da massa de pão, pois há a formação de gás carbônico na mistura, fazendo com que ela se expanda, ou seja, aumente de tamanho (THIS, 2007). Parte do gás que é formado não fica retido na massa de pão, fazendo com que essa, ao final do processo reacional, tenha menor massa do que no início.

Para verificar a perda de massa (medida física) da massa de pão contendo o fermento, as experiências a serem comparadas deveriam estar em sistema aberto, uma vez que em sistema fechado, após a reação de fermentação, o gás carbônico que "escapa" dessa mistura ficaria retido no sistema e a massa (medida física), após o final do processo reacional, seria a mesma do início, o que corrobora a Lei de Conservação de Massas proposta por Lavoisier: "Quando uma reação química é realizada em um recipiente fechado, a massa dos produtos (após a reação química) é igual à massa dos reagentes (antes da reação química)" (MAIA; BIANCHI, 2007, p.186).

Dentre os 46 estudantes investigados, $E_{06}$ não respondeu à questão e, $E_{29}$ e $E_{40}$ não apresentaram explicações às suas respostas. A produção escrita dos estudantes que explicaram suas respostas foram analisadas e agrupadas em categorias, apresentadas no Quadro 9.

$\mathrm{Na}$ investigação da produção escrita referente à questão Massa de Pão, verificou-se que 9 estudantes, dos 12 que assinalaram a resposta correta, apresentaram justificativas semelhantes às explicações dos estudantes que assinalaram outras alternativas de resposta. Assim, independentemente de terem assinalado a alternativa correta, suas justificativas foram alocadas nas mesmas categorias em que foram agrupadas as produções escritas dos estudantes que erraram a questão, exceto na Categoria $5\left(E_{22}, E_{25}\right.$ e $\left.E_{43}\right)$.

Os estudantes $E_{22}, E_{25}$ e $E_{43}$ demonstraram compreender que se deve comparar uma experiência contendo fermento e a outra não, ambas em sistema aberto, indicando a ocorrência de uma reação química no sistema que contém o fermento, podendo inferir que este ingrediente é o responsável pela perda da massa do pão.

De acordo com a análise das produções escritas, verificou-se que nenhuma delas apresentou, de forma minuciosa, explicações que justificassem corretamente o fenômeno investigado (processo de fermentação da massa de pão), em que as experiências a serem comparadas deveriam estar em sistema aberto, uma com e a outra sem fermento. Mediante o apresentado no Quadro 9, verificou-se que os estudantes construíram suas justificativas influenciados pelo tamanho da massa de pão ilustrada em cada uma das quatro experiências; ou apresentaram explicações que não caracterizam uma justificativa da resposta, ou seja, apenas descreveram a ilustração da imagem da questão relacionada à 
alternativa assinalada; ou sugeriram que para verificar o efeito do fermento na massa de pão, a mistura deveria estar em sistema fechado ou aberto, ou ainda, na presença ou não de ar ou gás oxigênio.

Quadro 9 - Categorias que emergiram a partir das respostas dos à questão sobre Massa de Pão

\begin{tabular}{|c|c|c|}
\hline $\begin{array}{l}\text { Categorias / } \\
\text { Estudantes }\end{array}$ & Descrição & Exemplos de Produções Escritas \\
\hline $\begin{array}{l}\text { 1. Imagem da } \\
\text { questão } \\
\text { (A: } E_{38 ;} B: E_{10} ; E_{30} ; E_{33} ; \\
E_{41 ;} \text { C: } E_{02} ; E_{26} ; E_{37 ;} \text { D: } \\
\left.\quad E_{01} ; E_{35} ; E_{39}\right)\end{array}$ & $\begin{array}{l}\text { Explicações que levam } \\
\text { em conta o tamanho } \\
\text { da massa de pão } \\
\text { ilustrada em cada } \\
\text { uma das quatro } \\
\text { experiências da } \\
\text { imagem da questão. }\end{array}$ & $\begin{array}{l}\text { A: Porque com o recipiente fechado, com ou sem } \\
\text { fermento, a massa não diminui, o problema não está no } \\
\text { fermento. }\left(E_{38}\right) \\
\text { B: Porque enquanto o recipiente está fechado a massa } \\
\text { tem o mesmo peso, tamanho. Já quando o recipiente está } \\
\text { aberto ela se diminui, pois o dióxido de carbono sai do } \\
\left.\text { recipiente e ela não cresce mais. ( } E_{30}\right) \\
\text { C: A experiência sem fermento, porque mostra que } \\
\text { tampado ele cresce e sem tampa não, então o fermento } \\
\text { não éo causador. }\left(E_{26}\right) \\
\text { D: Porque só as duas que a massa diminuiu. }\left(E_{35}\right)\end{array}$ \\
\hline $\begin{array}{l}\text { 2. Descrição da } \\
\text { imagem da questão } \\
\left(A: E_{09 ;} E_{44} ; B: E_{05} ; E_{17} ;\right. \\
E_{20} ; E_{36 ;} E_{46} ; C: E_{15} D: \\
\left.E_{14}\right)\end{array}$ & $\begin{array}{l}\text { Apenas descreve a } \\
\text { ilustração relacionada } \\
\text { à alternativa } \\
\text { assinalada. }\end{array}$ & $\begin{array}{l}\text { A: Porque os dois recipientes estão fechados, do jeito que } \\
\text { deixam a massa de pão para crescer. Porém, um tem } \\
\left.\text { fermento e o outro não. ( } E_{09}\right) \\
\text { D: Porque os dois estão sem tampa e um está com } \\
\text { fermento e o outro sem. }\left(E_{14}\right)\end{array}$ \\
\hline $\begin{array}{l}\text { 3. Influência do ar } \\
\text { ou gás oxigênio } \\
\text { (A: } E_{19} ; E_{44} ; B: E_{16} ; E_{23} ; \\
\left.E_{45} ; D: E_{07} ; E_{31}\right)\end{array}$ & $\begin{array}{l}\text { Explicações indicando } \\
\text { que a presença ou a } \\
\text { ausência de ar ou gás } \\
\text { oxigênio influencia na } \\
\text { ocorrência da reação } \\
\text { de fermentação. }\end{array}$ & $\begin{array}{l}\text { A: Ele só quer descobrir se é o fermento que causa a } \\
\text { perda, e a massa não pode ter contato com o oxigênio. } \\
\left(E_{44}\right) \\
\text { D: Porque precisa ar na mistura para o fungo agir. }\left(E_{07}\right)\end{array}$ \\
\hline $\begin{array}{l}\text { 4. Sistema fechado / } \\
\text { aberto } \\
\text { (A: } E_{11 ;} E_{12} ; E_{13} ; B: E_{42 i} \\
\left.\text { C: } E_{04} D: E_{03}\right)\end{array}$ & $\begin{array}{l}\text { Explicações indicando } \\
\text { que o processo de } \\
\text { fermentação é } \\
\text { favorecido pelo } \\
\text { sistema fechado ou } \\
\text { aberto. }\end{array}$ & $\begin{array}{l}\text { A: Pois é necessário deixar fechado para ocorrer } \\
\text { fermentação, assim ele poderia ver se o fermento que } \\
\text { causa tal perda. }\left(\mathrm{E}_{12}\right) \\
\text { D: Porque um seria com o fermento e o outro não, e } \\
\text { assim poderia responder, com o recipiente aberto para } \\
\text { melhorar o desenvolvimento da massa, pra que ela } \\
\text { cresça. }\left(\mathrm{E}_{03}\right)\end{array}$ \\
\hline $\begin{array}{l}\text { 5. Reação química } \\
\left(D: E_{22} ; E_{25} ; E_{43}\right)\end{array}$ & $\begin{array}{c}\text { Explicações que } \\
\text { sugerem a ocorrência } \\
\text { de uma reação } \\
\text { química na fabricação } \\
\text { do pão. } \\
\end{array}$ & $\begin{array}{l}\text { D: Uma mistura com fermento e outra sem fermento, } \\
\text { com o recipiente aberto. Assim, ocorrerá uma reação } \\
\text { química no que há fermento, assim poderá comparar } \\
\text { ambas. }\left(\mathrm{E}_{43}\right)\end{array}$ \\
\hline $\begin{array}{l}\text { 6. Explicações } \\
\text { confusas } \\
\text { (B: } E_{08 i} E_{32 ;} \text { C: } E_{27} ; \\
E_{28 i} \text { D: } E_{21} ; B \text { e } C: E_{18 i} \\
\left.\text { A e D: } E_{34}\right)\end{array}$ & $\begin{array}{c}\text { Explicações que } \\
\text { apresentam confusão. }\end{array}$ & $\begin{array}{l}\text { D: O recipiente } 3 \text { está com o fermento e aberto, e o } 4 \text { está } \\
\text { com o fermento, então eu acho que o fermento não } \\
\text { interfere na perda da massa. }\left(E_{21}\right) \\
\mathrm{C} \text { : Ele deve comparar um recipiente tampado com } \\
\text { fermento e um aberto sem fermento. }\left(\mathrm{E}_{28}\right)\end{array}$ \\
\hline
\end{tabular}

Obs.: As letras maiúsculas em negrito indicam a alternativa assinalada na resposta de cada estudante.

Nas considerações finais, são apresentadas as reflexões e as ponderações a respeito da investigação da produção escrita de estudantes do Ensino Médio, nas 3 questões de Ciências do PISA que abordam conceitos químicos. 


\section{Considerações finais}

Neste artigo, foi apresentado um estudo de natureza qualitativa que teve o objetivo de investigar a produção escrita de estudantes do Ensino Médio em três questões de Ciências do PISA que envolvem conceitos específicos de Química, das temáticas Ozônio, Brilho Labial e Massa de Pão, respectivamente.

Na primeira questão, de tema Ozônio, por meio da produção escrita dos estudantes, buscou-se evidenciar o entendimento e a compreensão dos mesmos acerca de alguns processos químicos expressos em uma ilustração que envolve a combinação de átomos e moléculas para a formação de novas moléculas. Na segunda questão, de tema Brilho Labial, investigou-se a compreensão acerca de evidências científicas expressas nas produções escritas dos estudantes, a partir de seu entendimento das informações contidas no suporte e no enunciado da questão, a fim de comparar as quantidades de ingredientes utilizadas nas receitas de dois cosméticos. E, por meio das explicações dos estudantes para a terceira questão, de tema Massa de Pão, buscou-se evidenciar a compreensão acerca do fenômeno investigado (processo de fermentação), comparando experiências em sistema aberto e fechado relacionadas à identificação da variável a ser modificada (presença/ausência de fermento).

Com base na interpretação da produção escrita dos 46 estudantes, apenas dois (4,35\% dos investigados) apresentaram pelo menos um dos aspectos de respostas esperados para a questão de tema Ozônio, de acordo com os referenciais de correção do PISA, enquanto para a questão de tema Brilho Labial, 17 estudantes (36,96\% dos investigados) a responderam corretamente. Apesar de 12 estudantes terem respondido corretamente à questão de tema Massa de Pão, foi considerado que apenas três (6,52\% dos investigados) tenham mobilizado, em suas produções escritas, conhecimentos referentes ao fenômeno científico envolvido.

As produções escritas foram analisadas e agrupadas em categorias: para as questões de tema Ozônio (7 categorias) e Brilho Labial (7 categorias), respectivamente, apenas as produções escritas que não contemplaram os aspectos de respostas esperados do PISA; e todas as produções escritas da questão de tema Massa de Pão (6 categorias).

Mediante a análise realizada, verificou-se que a maioria dos estudantes detêm conhecimentos de alguns conceitos abordados, mas apresentaram dificuldades em utilizar uma linguagem científica para explicar, por exemplo, fenômenos químicos apresentados nas figuras das questões (Questões de tema Ozônio e Massa de Pão, respectivamente), ou não conseguiram lidar corretamente com as informações da questão para produzir argumentos e conclusões fundamentados em evidências científicas (Questão de tema Brilho Labial).

Com base nas dimensões nas quais o Letramento Cientifico é determinado pelo PISA, e de acordo com o estudo apresentado, constatou-se que os estudantes investigados apresentam dificuldades nos conteúdos científicos, o que interfere no interesse e atenção frente à Ciência e Tecnologia, e na inabilidade de utilizarem os conhecimentos para interpretar processos que envolvem situações da vida cotidiana. Nesse sentido, pode-se inferir que eles não tenham atingido o nível de proficiência 3 do PISA, uma vez que boa parte desses estudantes não conseguiu "recorrer a conhecimento de conteúdo de moderada complexidade para identificar ou formular explicações de fenômenos conhecidos" (OCDE, 2016, p. 49). Alguns estudantes apenas apresentaram explicações científicas que resultaram de uma evidência apresentada, como exigido na questão de tema Brilho Labial. 
As dificuldades dos estudantes em compreenderem as questões e em produzirem respostas/explicações para as mesmas, podem estar relacionadas à não mobilização de alguns aspectos do Letramento Científico como o entendimento de determinados conceitos científicos, alguns processos de investigação, e o desenvolvimento de atitudes e capacidades de pensamento necessárias à tomada de decisões. Tais aspectos ainda são pouco contemplados na maioria das aulas de Ciências, sobretudo no ensino de Química, uma vez que os conteúdos são apresentados de forma fragmentada e sem muitas relações com a origem dos conceitos e com o cotidiano dos estudantes (MILARÉ; ALVES FILHO, 2010).

Diante do estudo apresentado, defende-se que ao conhecer a produção escrita de seus estudantes, o professor tem a possibilidade de refletir sobre a sua prática docente, de modo a repensar o modelo de ensino que adota e suas práticas avaliativas (ANTUNES; MENDES, 2018) no sentido de possibilitar a promoção de uma educação em Ciências além das ações tradicionalistas de ensino em que há um grande acúmulo de conhecimentos (SCHNETZLER, 2002), passando a utilizar abordagens metodológicas que prezem pela construção da Ciência a partir de práticas investigativas que contemplem atividades argumentativas (PEZARINI; MACIEL, 2018) e/ou problematizadoras (CARVALHO, 2013), ou seja, práticas que possibilitem uma educação em Ciências por meio do Letramento Científico. Entretanto, vale ressaltar que a atuação do professor dependerá do conhecimento e contato estabelecidos com essas práticas de ensino, especialmente na Formação Inicial ou na Formação Continuada, ou devido a alterações nos programas escolares de Ciências.

Nessa perspectiva, saliente-se a importância de que as aulas de Ciências contemplem o Letramento Científico, fazendo com que os estudantes sejam capazes de desenvolver ideias e maneiras científicas de pensar, resolver problemas e tomar decisões na vida pessoal, cívica e profissional, uma vez que o conhecimento de Ciências é indispensável para solucionar inúmeros problemas da vida moderna em um mundo globalizado. Ressalte-se, ainda, que o ensino de Ciências possibilite desenvolver conhecimentos e habilidades que possam ir além do aspecto relacionado ao conteúdo e considere abordar as dimensões procedimentais e contextuais relacionadas ao conhecimento científico.

\section{Referências}

ANTUNES, T. P.; MENDES, M. T. Desenvolvimento profissional de um professor ao (re)elaborar uma prova escrita de matemática. Amazônia - Revista de Educação em Ciências e Matemáticas, v. 14, n. 31, p. 22-38, 2018.

BARDIN, L. Análise de conteúdo. São Paulo: Edições 70, 2016.

BARROS, M. A. S. Obstáculos epistemológicos: O conceito de quantização de energia nos livros didáticos de química do ensino médio. In: ENCONTRO NACIONAL DE ENSINO DE QUÍMICA, 15., 2010. Anais... Brasília, 2010.

BRASIL. INEP. PISA 2000: Relatório Nacional. Brasília: SIG, 2001. Disponível em: <http://download.inep.gov.br/download/internacional/pisa/PISA2000.pdf>. Acesso em: 06 fev. 2020. 
BRASIL. INEP. Matriz de avaliação de ciências. Brasília: SIG, 2012. Disponível em: <http://download.inep.gov.br/acoes_internacionais/pisa/marcos_referenciais/2013/matriz_av aliacao_ciencias.pdf>. Acesso em: 05 fev. 2020.

BRASIL. MEC. INEP. DAEB. Relatório Brasil no PISA 2018: versão preliminar. Brasília: Inep/MEC, 2019.

BOIETTI, F. C. D.; RIBAS, J. F.; SALAMANCA NETO, C. A. R.; STANZANI, E. L. Uma análise das questões que abordam conceitos químicos do caderno de Ciências do PISA. In: CONGRESSO NACIONAL DE AVALIAÇÃO EM EDUCAÇÃO, 3., 2014, Bauru. Anais... Bauru: UNESP, 2014.

CARVALHO, A. M. P. (Org.). Ensino de ciências por investigação: condições para implementação em sala de aula. São Paulo: Cengage Learning, 2013.

CELESTE, L. B. A produção escrita de alunos do ensino fundamental em questões de matemática do PISA. 2008. 88 f. Dissertação (Mestrado em Ensino de Ciências e Educação Matemática) - Universidade Estadual de Londrina, Londrina, 2008.

MAIA, D. J.; BIANCHI, J. C. A. Química geral: fundamentos. São Paulo: Pearson Prentice Hall, 2007.

MILARÉ, T.; ALVES FILHO, J. P. A Química disciplinar em ciências do 90 Ano. Química Nova na Escola, v. 32, n.1, p. 43-52, 2010.

NARDI, R.; ALMEIDA, M. J. P. M. Analogias, leituras e modelos no ensino da ciência: a sala de aula em estudo. São Paulo: Editora Escrituras, 2006.

NRC - NATIONAL RESEARCH COUNCIL. A Framework for K-12 Science Education: Practices, Crosscutting Concepts, and Core Ideas. Committee on Conceptual Framework for the New K-12 Science Education Standards, 2012.

OCDE. Brasil no PISA 2015: análises e reflexões sobre o desempenho dos estudantes brasileiros. São Paulo: Fundação Santillana, 2016. Disponível em: <http://download.inep.gov.br/acoes_internacionais/pisa/resultados/2015/pisa2015_completo _final_baixa.pdf>. Acesso em: 06 fev. 2020.

OECD (Paris). PISA 2006 - Estrutura da Avaliação: Conhecimentos e habilidades em Ciências, Leitura e Matemática. São Paulo: Editora Moderna, 2007. 189 p.

OECD. PISA 2015: Matriz de Avaliação de Ciências. 2013. Disponível em: <http://download.inep.gov.br/acoes_internacionais/pisa/marcos_referenciais/2015/matriz_de _ciencias_PISA_2015.pdf>. Acesso em: 06 fev. 2020.

PEREGO, F. O que a produção escrita pode revelar? Uma análise de questões de matemática. 2006. 126 f. Dissertação (Mestrado em Ensino de Ciências e Educação Matemática) Universidade Estadual de Londrina, Londrina, 2006.

PEZARINI, A. R.; MACIEL, M. D. As dimensões da argumentação no Ensino de Ciências em pesquisas de 2007 a 2017: um olhar para a caracterização e para as ferramentas metodológicas para estudar esta temática. Amazônia - Revista de Educação em Ciências e Matemáticas, v. 14, n. 32, p. 61-77, 2018.

RIBAS, J. F.; SALAMANCA NETO, C. A. R.; BROIETTI, F. C. D.; STANZANI, E. L. Investigando a produção escrita de estudantes do Ensino Médio em uma questão de Ciências do PISA. In: 
CONGRESSO PARANAENSE DE EDUCAÇÃO QUÍMICA, 4., 2015, Curitiba. Anais... Curitiba: UFPR, 2015.

SALAMANCA NETO, C. A. R.; RIBAS, J. F.; BROIETTI, F. C. D.; STANZANI, E. L. Uma análise das questões de Ciências do PISA. In: ENCONTRO NACIONAL DE ENSINO DE QUÍMICA, $17 .$, 2014, Ouro Preto. Anais... Ouro Preto: UFOP, 2014.

SASSERON, L. H.; CARVALHO, A. M. P. Alfabetização científica: uma revisão bibliográfica. Investigações em Ensino de Ciências, v. 16, n. 1, p. 59-77, 2011.

SCHNETZLER, R. P. A pesquisa em ensino de química no Brasil: conquistas e perspectivas. Química Nova, v. 25, supl. 1, p. 14-24, 2002.

TENREIRO VIEIRA, C.; VIEIRA, R. M. Literacia e pensamento crítico: um referencial para a educação em ciências e em matemática. Revista Brasileira de Educação, v. 18, n. 52, p. 163188, 2013.

THIS, H. Um cientista na cozinha. São Paulo: Ática, 2007. 